

\section{DISCLAIMER}

This report was prepared as an account of work sponsored by an agency of the United States Government. Neither the United States Government nor any agency Thereof, nor any of their employees, makes any warranty, express or implied, or assumes any legal liability or responsibility for the accuracy, completeness, or usefulness of any information, apparatus, product, or process disclosed, or represents that its use would not infringe privately owned rights. Reference herein to any specific commercial product, process, or service by trade name, trademark, manufacturer, or otherwise does not necessarily constitute or imply its endorsement, recommendation, or favoring by the United States Government or any agency thereof. The views and opinions of authors expressed herein do not necessarily state or reflect those of the United States Government or any agency thereof. 


\section{DISCLAIMER}

Portions of this document may be illegible in electronic image products. Images are produced from the best available original document. 


\section{Materials Department \\ Product Development Program}

for 1966

This annual report summarizes the technical progress and evaluates the results of the product development programs conducted by the Materials Department in 1966. The program included the following seven projects:

$\begin{array}{ll}6-59316-1 & \text { Liquid Metal Studies } \\ 6-59316-3 & \text { Refractory Carbide Fuel Development } \\ 6-59316-5 & \text { Special Problems in Nuclear Rocket Fuel } \\ 6-59316-8 & \text { High Temperature Semi-Conductors } \\ 6-59316-41 & \text { Composite Material Development } \\ 6-59316-45 & \text { Vapor Deposition Studies } \\ 6-59316-46 & \text { Out-of-Vacuum Electron Beam Welder }\end{array}$

The main objective of these efforts was to develop an in-house capability in specific technology areas which can be used to obtain contract support for the laboratory. This objective to a large part has been achieved and in addition, peripheral benefits, such as generation of data, identification of the Astronuclear Laboratory as a participant in a field through papers and presentations, support of system studies, and increased customer contact can be defined. 
We Astronuclear

WANL-TMI-1763

Title:

LIQUID METAL STUDIES

Project No.:

$6-59316-1$

R. T. Begley, R. L. Ammon, F. G. Arcella

I. Objective: Develop capability at WANL to support other WANL departments in the ir contract and proposal efforts which require liquid metal technology. Provide a basis to compete for materials contracts in the liquid metal area.

\section{Technical Progress}

Two areas were defined for active study during 1966. First we decided to upgrade the operating temperature capability of the laboratory and to replace the loading system for the alkali metal facility. Both of these areas were "home built" in the early days of WANL and both had outlived their usefulness due to the rapid advance of liquid metal technology. In the other part of our product development work, we decided to explore oxygen partitioning in alkali systems.

1. By the end of the year, we had put on test two ion-pumped high temperature capsule furnaces. These units have been checked out and will be available for capsule corrosion testing in 1967. The installation of our new alkali liquid metal handling system was $95 \%$ completed by the end of the year.

2. The distribution of oxygen in a system is of great concern considering the role that oxygen has been found to play in the corrosion process. In spite of this obvious need little work has been done in this area, and what has been done is in large disagreement with theoretical values determined from uncertain thermodynamic data. The determination of oxygen partitioning by experimental means has also been hampered by inadequate analytical procedures.

A technique developed by MSAR, has shown that the solubility of oxygen in cesium produces a linearly proportional drop in freezing point. The 
depression of the freezing point is due to oxygen in solution and is not affected by other impurities such as carbon or nitrogen. This technique is applicable to rubidium and cesium which unlike sodium and potassium have a large solubility at low temperatures.

Hewlitt-Packard recently has developed a quartz thermometer capable of measuring temperatures to $\pm 0.0001^{\circ} \mathrm{C}$. This instrument was acquired on loan and a series of experiments were conducted to evaluate the feasibility of using the quartz thermometer to measure the oxygen content of cesium. A stainless steel capsule was loaded with cesium and its freezing point was determined. In four runs, the freezing point arrest at $1530 \mathrm{ppm}$ oxygen occurred with less than a $3 \%$ deviation. After baking the capsule at $800^{\circ} \mathrm{C}$ for 48 hours three freezing point determinations were conducted. Each indicated $63 \mathrm{ppm}$ oxygen with excellent reproducibility. Additional experimental determinations with capsules containing as little as $14 \mathrm{ml}$ of cesium were as equally reproducible. The advantages of such an analytical technique are many. No elaborate chemical laboratory with specialized people is required. Determinations are rapid and can be accomplished by a technician with a minimum amount of training. Oxygen can be determined in cesium without removing it from the system, thus permitting the oxygen content of cesium to be determined as a function of time.

The acquisition of a quartz thermometer has permitted WANL to carry out a meaningful program to determine the partitioning of oxygen in refractory metal-cesium systems in 1966. In addition heretofore unavailable thermodynamic data can be determined.

During the latter part of 1966 a thirteen zone-passed Cs bar was sent to APD-Waltz Mills for spectrographic analysis for $\mathrm{K}, \mathrm{Rb}, \mathrm{Cu}$ and other constituent impurities to establish concentration profiles along the length of the bar. Preliminary data indicate that zone refining of $C_{s}$ is feasible. 
In support of other activities at WANL, we were able to supply the manpower to put the NaK loop for the Compact Converter on-line and operate it successfully for approximately 3000 hours. During December plans were made to insert a second module into the system and to install flow meters into the line.

Support has also been given in the Weapons Effects and thermionic area.

\section{Summation of Costs}

During 1966, a total of $\$ 34,227$ was spend on Liquid Metal Studies.

IV. How the Work Benefited WANL

The eventual pay-off for our successful alloy development and welding programs will be the incorporation of this technology into large Rankine systems which make use of refractory metals and alkali metals for the heat transfer techniques. The knowledge gained from this product development program will enhance our technological ability to obtain such programs. 
Title:

Project No.:

\section{HIGH TEMPERATURE SEMI-CONDUCTORS}

6-59316-8

R. B. Campbell and L. Kroko

1. Objective: As a preliminary step to establishing WANL in the SiC device technology area, a project was initiated to plan a minimum laboratory, identify needed equipment and its location, investigate the patent position, support negotiations with various customer and coordinate our activities with the (U) R\&D Center.

II. Technical Progress

1. Laboratory space requirements were defined and the short and long range equipment items were identified for the 196701968 targets.

2. Surplus equipment was procured from the R\&D Center. The $\mathrm{SiC}$ crystal growing furnace was installed and made ready for check out.

3. Several negotiations were carried out, in concert with the R\&D Center, with the USAF, Fenwal, Pyrotector, Hughes, NASA-Lewis and ERC, etc. An assessment of the potential market was made and target objectives for 1967 were set.

4. Negotiations with an added professional employee took place and an offer was made to him and he accepted.

\section{Summation of Costs}

A total of $\$ 12,886$ was spend during 1966. All of this was incurred using the part time services of two scientists from the R\&D Center. 


\section{w Astronuclear Laboratory}

WANL-TMI-1763

IV. Benefit to WANL

Identification of WANL to a variety of new customers was initiated. Having this advanced solid state technology available to WANL should prove of major value in establishing our over-all systems capability, increasing our participation in specific weapons areas, and hopefully in starting a new product line for WANL. 
Title:

Project No.:

I. Objectives:

\section{REFRACTORY CARBIDE FUEL DEVELOPMENT}

6-59316-3

\author{
J. M. Tobin, L. Fleischer, W. Brizes
}

II. Technical Progress

The high temperature carbide and fuel development effort for 1966 was directed toward six areas. They were:

\section{High Temperature Carbon Diffusion Studies}

The comparative study of the reaction kinetics and carbon diffusion rates in transition element monocarbides was completed with the final elements $T i$, $\mathrm{HF}$, and $\mathrm{V}$. The diffusion coefficients of carbon were determined in overlapping temperature ranges from $1600^{\circ}$ to $3000^{\circ} \mathrm{C}$. Five topical reports and several journal articles have been written and published.

\section{Carbide Mechanical Properties at High Temperatures}

Processes for casting of specimens of pure monocarbides of six transition elements and of the hypereutectic $\mathrm{ZrC}-\mathrm{C}, \mathrm{HfC}-\mathrm{C}$ and $\mathrm{NbC}-\mathrm{C}$ compositions were developed. The latter lead to a response to an Air Force request for proposal. The 100 per cent dense carbides prepared by the mold-melt process were used to determine unexpected ductility in the monocarbides at high temperatures. The approximate ductile-to-brittle transition temperature for $\mathrm{ZrC}, \mathrm{NbC}, \mathrm{TaC}$ and $\mathrm{NbC}$ were determined.

\section{Single Crystal Carbides}

Observations of recrystallization and grain growth in carbides at high temperatures lead to a novel method of growing monocarbide single crystals of $\mathrm{ZrC}$ and $\mathrm{NbC}$. The process was proposed in response to an Air Force RFP to prepare six 
different single crystal carbides of high quality. A contract was obtained $(\$ 120,000)$ and the work is progressing on our project number XAL-70096-AL.

\section{Ternary Phase Diagram}

The ternary refractory carbide fuel system $\mathrm{U}-\mathrm{Zr}-\mathrm{C}$ was studied in the limited region required to determine the liquidus surfaces and valleys in the carbon rich part of the equilibrium diagram. High temperature thermal analysis was used. AClass II reaction temperature was found, indicating liquid formation at $2405^{\circ} \mathrm{C}$ over a broad composition range.

\section{Brazing of Carbides}

Methods of brazing $\mathrm{ZrC}$ to $\mathrm{ZrC}$ were developed using hot pressing, and liquid $\mathrm{Zr}$ metal. The homogenized bond could not be distinguished metallographically.

\section{Carbide Fabrication}

Uranium rich mixed carbide fuel pellets for thermionic applications, such as $90 \mathrm{UC}-10 \mathrm{ZrC}$ were fabricated with the low density and interconnected porosity required for fission gas release.

Pure $\mathrm{NbC}$ and $\mathrm{TaC}$ powder compacts were sintered to 95 per cent of theoretical density in 4 hours at $3000^{\circ} \mathrm{C}$. Previous densities were limited to 80 per cent before the advent of higher temperature capability.

\section{Summation of Costs}

A total of $\$ 7,920$ actual cost was spent on this product development effort in 1966.

IV. How the Work Benefited WANL

It has enabled WANL to be recognized as a contributor to high temperature research in transition monocarbides. Several topical reports, journal articles, a patent application and an Air Force contract $(\$ 120,000)$ on carbide single crystals resulted from this work. 
Title:

SPECIAL PROBLEMS IN NUCLEAR ROCKET FUEL

Project No.:

$6-59316-5$

J. M. Tobin, L. Fleischer

I. Objectives: To provide capability and awareness in advanced nuclear rocket fuel technology.

\section{Technical Progress}

The experimental program was limited to development of a process for fabricating high density, low $U$ loading, advanced rocket fuel of the UC- $\mathrm{ZrC}$ type. A practical process of liquid phase sintering of a novel type using $\mathrm{Zr}$ liquid metal phase during sintering resulted in homogeneous mixed carbide fuel was disclosed and a patent is being applied for. The fuel was shown to be resistant to hydrogen corrosion.

\section{Actual Costs}

A total cost of $\$ 2,631$ was spent on this product development effort in 1966.

IV. How the Work Benefited WANL

As far as is known, no other fuel fabrication process can produce mixed UC-ZrC fuel in the high qaulity necessary for advanced rocket fuel at this time. 
Title:

Project No.:
COMPOSITE MATERIALS

$6-59316-41$

\author{
R. T. Begley, D. L. Harrod, J. A. Cornie
}

I. Objective: Develop capability at WANL to compete in the composite material area.

II. Technical Progress

Research and development in composite materials in the U.S.A. has continued at a very high level. WANL had set a two pronged objective in 1966 (a) to obtain a Government contract and (b) to contribute to some aspects of NERVA advanced materials requirements.

We did not obtain the outside support we had hoped for although we did place second on three competitive RFQ's and thus enhanced our stature in this very competitive area. We were able, on the other hand, to apply the skills developed on product development in contributing to the development of new shielding, control plate, and cluster plate materials.

Specifically, active work was carried out in the following areas:

1. Research continued on studies of creep behavior of metal matrix fiber reinforced composites.

2. Various techniques for producing oriented fibers in metallic matrices were investigated.

3. An analytical study of the role of interfaces in composites was carried out and a technical paper was presented at the National meeting of SAMPE.

4. Experimental work in the following areas was conducted.

a) Fabrication techniques for composites.

b) Studies of matrix-fiber compatibility and interface characteristics.

c) Creep tests of aluminum reinforced with tungsten. 
(w) Astronuclear

Laboratory

WANL-TMI-1763

\section{Summation of Costs}

In 1966 the actual costs were $\$ 22,189$.

\section{Benefits to WANL}

The studies on fiber-matrix interface behavior and on the mechanical properties of composites provide a strong technological base to develop the specific "designed" materials for advanced NERVA requirements. 
Title:

Project No.:

\title{
CHEMICAL VAPOR DEPOSITION
}

$$
6-59316-45
$$

\author{
A. Hoppe, W. Bryant, S. Orbon
}

I. Objective: This project is set up to cover the development of specific chemical vapor deposition (CVD) techniques to meet the requirements of particular problems.

II. Technical Progress

During 1966, the tasks that were worked on include:

a) Protection of isotope encapsulation materials from long time oxidation.

b) Oxidation protection of tantalum alloys from short time oxidation.

c) Improvement of emitter surface for thermionic reactors.

These three tasks are discussed below.

1. Protection of isotope encapsulation materials from long time oxidation effects.

During December it was requested that a background be developed on cladding radioisotope capsules. Questions were raised on how to coat T-111 or ASTAR $811 \mathrm{C}$ with platinum for oxidation protection, on the need for a diffusion barrier to prevent intermetallic compound formation, and how to deposit this diffusion barrier and/or cladding. A literature survey was made, several preliminary experiments depositing platinum on tantalum alloys were made, and apparatus designed and constructed for more sophisticated platinum and thoria experiments.

Preliminary evidence indicates that a $\mathrm{ThO}_{2}$ diffusion barrier is necessary. The two most promising methods of application of $\mathrm{ThO}_{2}$ were plasma spraying and thermal decomposition of thorium tetra-tertiary butoxide. For application of platinum to $\mathrm{ThO}_{2}$, two alternate approaches were determined to be feasible: one consisted of spraying an aqueous solution of $\mathrm{PtCl}_{2}$ onto the substrate, which is held at approximately $150-200^{\circ} \mathrm{C}$. Upon this 
(approximately $1 \mu$ ) coating of platinum, a heavier coating of platinum is electroplated from either aqueous solution or fused salts. The second approach is simply a mechanical enclosure of platinum, e.g., a can.

2. Protection of tantalum from short time environmental effects.

Tungsten coated tantalum based alloys are finding use in high temperature, hydrogen bearing atmospheres. Tungsten is also being used as a precoating for oxidation resistant coatings (such as $\mathrm{WSi}_{2}$ ) on tantalum alloys.

The coating of this substrate material presents a problem, however. The chemical vapor deposition of tungsten is by the hydrogen reduction of $\mathrm{WF}_{6}$ at about $620^{\circ} \mathrm{C}$. At this temperature tantalum alloys rapidly absorb sufficient quantities of $\mathrm{H}_{2}$ to embrittle them. For this reason it was necessary to study the effect on the ductile-brittle behavior of various procedures in heating tantalum alloy substrates to the coating temperature. (Once tungsten begins to deposit the substrate is safe from embrittlement). The effect of a post coating anneal was also investigated.

Specimens of T-111 (2-1/4" $\left.\times 1 / 2^{\prime \prime} \times 0.040^{\prime \prime}\right)$ were annealed for 1 hour at $1650^{\circ} \mathrm{C}$ at $1 \times 10^{-5}$ torr and ultrasonically cleaned in $\mathrm{M}-6$ solvent for 15 minutes. The start up procedures were as follows:

$$
\begin{gathered}
\text { Fast Start up in } \mathrm{H}_{2} \begin{array}{l}
\text { - Inductively heat to } 620^{\circ} \mathrm{C} \text { in } 35 \mathrm{sec} \text {. using } \mathrm{H}_{2} \\
\text { flow of } 500 \mathrm{cc} / \mathrm{min} .
\end{array} \\
\text { Slow Start up in } \mathrm{H}_{2}-\begin{array}{l}
\text { Inductively heat to } 620^{\circ} \mathrm{C} \text { in } 5 \mathrm{~min} \text {. using a } \mathrm{H}_{2} \\
\text { flow of } 500 \mathrm{cc} / \mathrm{min} .
\end{array} \\
\text { Slow Start up in } \mathrm{Ar}-\begin{array}{l}
\text { Resistance heat to } 620^{\circ} \mathrm{C} \text { in } 150 \mathrm{~min} \text {. using } \\
\text { purified Ar flow of } 2000 \mathrm{cc} / \mathrm{min} .
\end{array}
\end{gathered}
$$

These start up procedures were chosen because of their anticipated application to future coating jobs that could be done with existing equipment. Tungsten was deposited on each specimen to a thickness of 3 mils. Some specimens were post-coat annealed for 1 hour at $1650^{\circ} \mathrm{C}$ at $1 \times 10^{-5}$ torr. Evaluation consisted of bend testing with the bend angle after load removal being adopted as the measure of toughness and ductility. These bend test 
conditions were used:

$$
\begin{aligned}
& \text { Temperature = variable } \\
& \text { Span }=1.25^{\prime \prime} \\
& \text { Punch Radius }=0.025^{\prime \prime} \\
& \text { Cross-bead Speed }=1.0 \mathrm{inch} / \text { minute } \\
& \text { Fixed Deflection }=0.080^{\prime \prime}
\end{aligned}
$$

Normal bend test procedures (obtaining the angle at which the specimen first cracks) were not used. Data so obtained would be meaningless because the DBTT of is over room temperature and tensile cracks occur immediately.

The relative ductility of coated specimens were determined as a function of bend test temperature (Figure 1). As expected, the toughness and ductility decrease with temperature. Photomicrographs of a typical tensile fracture at the sharpest portion of the bends (region of maximum stress) are shown in Figures $l a, l b$ and $1 c$. Figure $l a$ is as deposited, $1 \mathrm{~b}$ was coated and annealed, and $1 \mathrm{c}$ had the tungsten ground off after coating and before bending.

Several conclusions can be made:

Only the slow start up in hydrogen with no post coat anneal shows a definite ductile-to-ductile transition temperature (of about $100^{\circ} \mathrm{F}$ ).

Post coat anneal ing is a very effective means of restoring ductility both because it removes hydrogen and relieves the tensile stress in the substrate caused by the great difference in thermal contraction of tungsten and $T-111$ as they cool from the coating temperature. The benefit is illustrated by the open versus closed squares, by the resistance to crack propagation in Figure la versus $1 b$ and by the open versus closed circles at $-320^{\circ} \mathrm{F}$.

The benefits of stress relief is shown by a comparison of the data for fast start in $\mathrm{H}_{2}$ with that for fast start in $\mathrm{H}_{2}$ plus post coat anneal. 
This difference is due in large part to stress relief and to some extent to hydrogen removal. Figure $l c$ is a photomicrograph of a room temperature bend specimen which was coated using the fast start up in $\mathrm{H}_{2}$ and then ground to remove the tungsten on the tension side. Obviously very little hydrogen embrittlement of the substrate occurs with the fast $\mathrm{H}_{2}$ start up. Therefore, the difference in crack propagation and ductility can largely be attributed to a combination of the tungsten acting as a strike concentrator, stress relief of the substrate, and to the effect of hydrogen on crack propagation during slow strain rate plastic deformation.

The room temperature bend, argon start-up specimen, displayed excellent ductility. This is attributed to a complete lack of hydrogen embrittlement.

$\mathrm{WSi}_{2}$ is generally acknowledged to be the best material for the protection of tantalum base alloys in high temperature oxidizing atmospheres. ( $U p$ to $3200^{\circ} \mathrm{F}$ the reaction depth rate in $\mathrm{WSi}_{2}$ exposed to air under one atmosphere is $0.10 \mathrm{mil} /$ hour or less). However, commercially available means for applying coatings of this material (pack siliciding preceded by any method of $W$ coating, electrophoretically deposited tungsten followed by vacuum siliconizing, direct electrophoretic depositing of $\mathrm{WS}_{2}$ ) produce one or mcre of the following defects:

a) substrate embrittlement

b) porous coatings

c) tungsten-poor coating (which is an oxygen bearing atmosphere readily converts to the low melting $\mathrm{SiO}_{2}$ )

d) edge and corner cracks in coating.

Chemical vapor deposition techniques developed at WANL can eliminate the first three defects and therefore will not be discussed further. The fourth defect presents the greatest problem since it leads to premature failure in oxidation testing. We have developed the solution to this problem. 
In Figure 2 (top photo) tungsten has been deposited on a T-111 substrate by our standard method. A silicon coating was then deposited according to

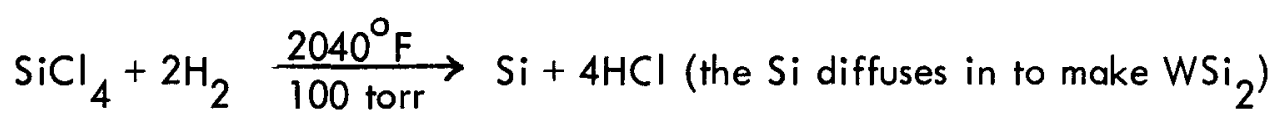

Note the corner cracks in the $\mathrm{WSi}_{2}$. These cracks have been sealed, however, by repeating the tungsten coating (middle photo). Alternate layers of silicon and tungsten were deposited to build up the coating to the desired thickness of 2-3 mils (bottom photo middle). Each tungsten layer has sealed the cracks in the underlying $\mathrm{WSi}_{2}$ layer and has prevented these cracks from propagating in a continuous manner. The composite coated specimen was solution annealed to yield a crack-free $\mathrm{WSi}_{2}$ coating (right photo). Whether the coating is tungstenrich or tungsten-poor has not been determined. The thin intermediate layer is probably $\mathrm{W}_{5} \mathrm{SI}_{3}$ since the thickness of the initially deposited tungsten layer was made thicker than would be required to form $\mathrm{WSi}_{2}$ with the first silicon layer.

An unannealed composite coated specimen was tested for oxidation resistance by heating to $3000^{\circ} \mathrm{F}$ in air with an oxycetylene torch for three intervals of 15 minutes each (left photo). Thermal stress patterns developed but the coating remained intact. Oxidation was confined to about the outer $20 \%$ of the composite coating. It is obvious from the photo that silicon diffusion into tungsten is rapid at this temperature.

A great deal of work is required to perfect this coating system (better control of layer thickness, oxidation testing of solution annealed coatings, etc.). However, we feel that with a month or two of concentrated effort (for which we have insufficient funds) we could be in position to sell a WSi ${ }_{2}$ coating program to Northrop Corporation, the Air Force, TRW, McDonnell Aircraft, or others.

\section{Thermionic Emitters}

One area of investigation which should add a great deal to the thermionic reactor program is the improvement of emitter surface uniformity to increase converter performance. Emission from conventional polycrystalline materials is nonuniform since 
each randomly oriented grain has a work function which varies with the crystallographic plane lying at the surface. A surface is needed that is essentially comprised of one crystallographic plane. Since the use of single crystals is out of the question, a preferentially oriented polycrystalline material must be used. Such a material can be produced by chemical vapor deposition.

Tungsten emitter surfaces having (110) planes parallel to the surface are needed for the diodes of the thermionic reactor. Other investigators have been able to influence the orientation of tungsten deposits by varying the deposition parameters. However, only (100) and (111) preferred orientations were produced and only the former was thermally stable. In their work only body centered cubic metals (which usually have a (100) recrystallization texture) were used as substrates. Tungsten coatings chemically vapor deposited onto our usual substrates (copper, recrystallized tungsten, 304 stainless steel) by our standard process $\mathrm{WF}_{6}+6 \mathrm{H}_{2} \underset{2 \mathrm{~mm} \mathrm{Hg}}{\stackrel{62}{\circ} \mathrm{C}} \mathrm{W}+6 \mathrm{HF}+3 \mathrm{H}_{2}$ invariably are highly oriented with the (100) planes parallel to the surface. Increasing the deposition temperature to $850^{\circ} \mathrm{C}$ and substituting $\mathrm{WCl}_{6}$ for $\mathrm{WF}_{6}$ produced a more randomly oriented coating which was controlled by the random substrate.

We have decided to concentrate our efforts on depositing tungsten onto material known to have a (110) preferred orientation - namely Hypersil (iron + silicon alloy) and evaporated molybdenum.

To date we have been unsuccessful in getting adherent deposits on Hypersil. This is possibly due to the presence of occluded gases (probably $W_{6}$ ), too great a mismatch in substrate-coating thermal contraction, incomplete removal of surface oxide from the substrate or a combination of several of these factors. Coating of the evaporated molybdenum substrate has not yet been attempted. However, we are optimistic since past work with tungsten coating of molybdenum has always given excellent results for substrate nucleation and epitaxial growth. 
(w) Astronuclear

Laboratory

WANL-TMI-1763

\section{Summation of Costs}

A total of $\$ 30,783$ was spent during 1966. Of this amount $\$ 12,000$ was spent in support of a general industry program being conducted at Battelle Memorial Institute. 


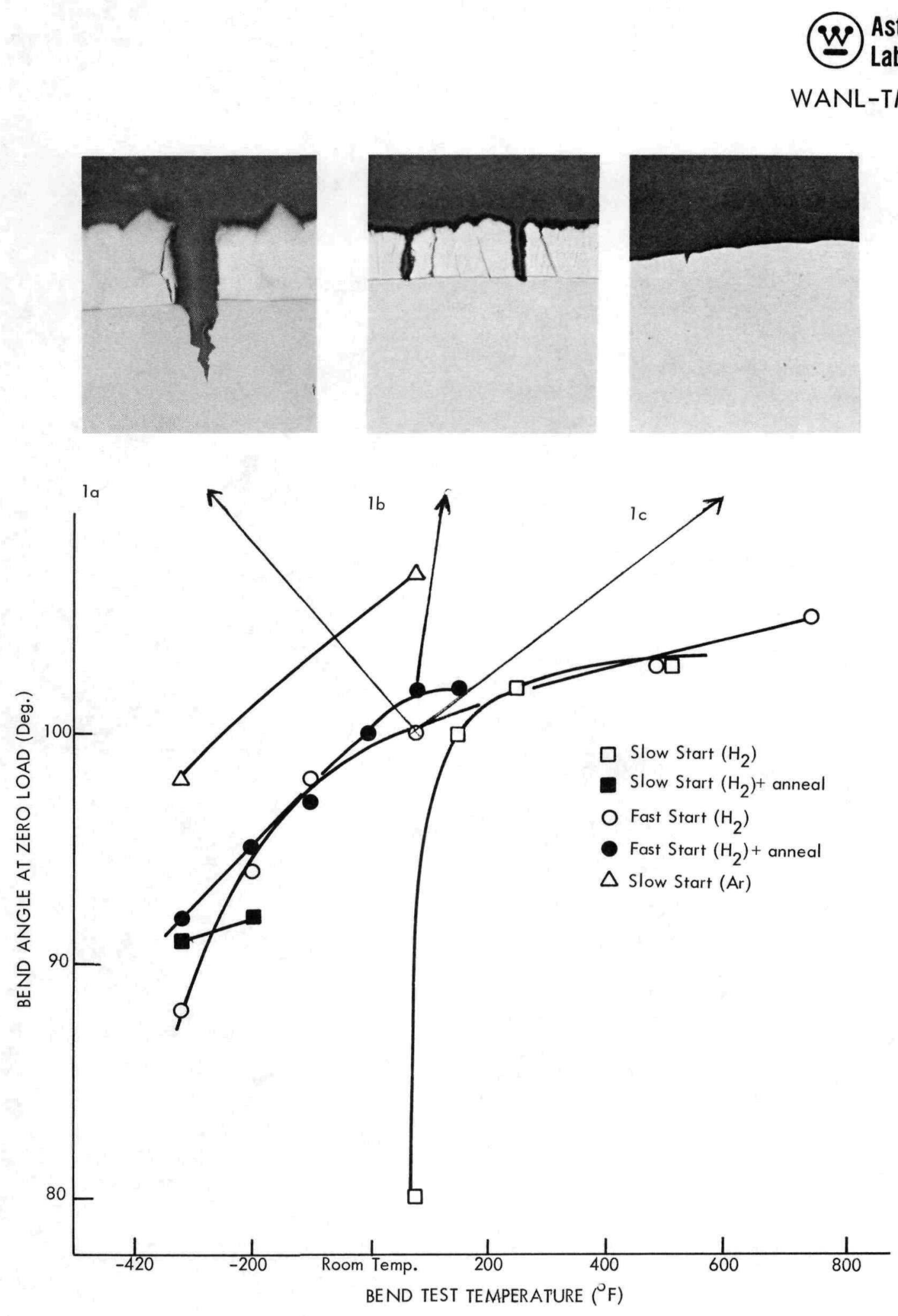

Figure 1

Ductile-Brittle Behavior as a Function of Start-up Procedure and Post-Coat Anneal 


\section{W Astronuclear \\ Laboratory}

WANL-TMI- 1763

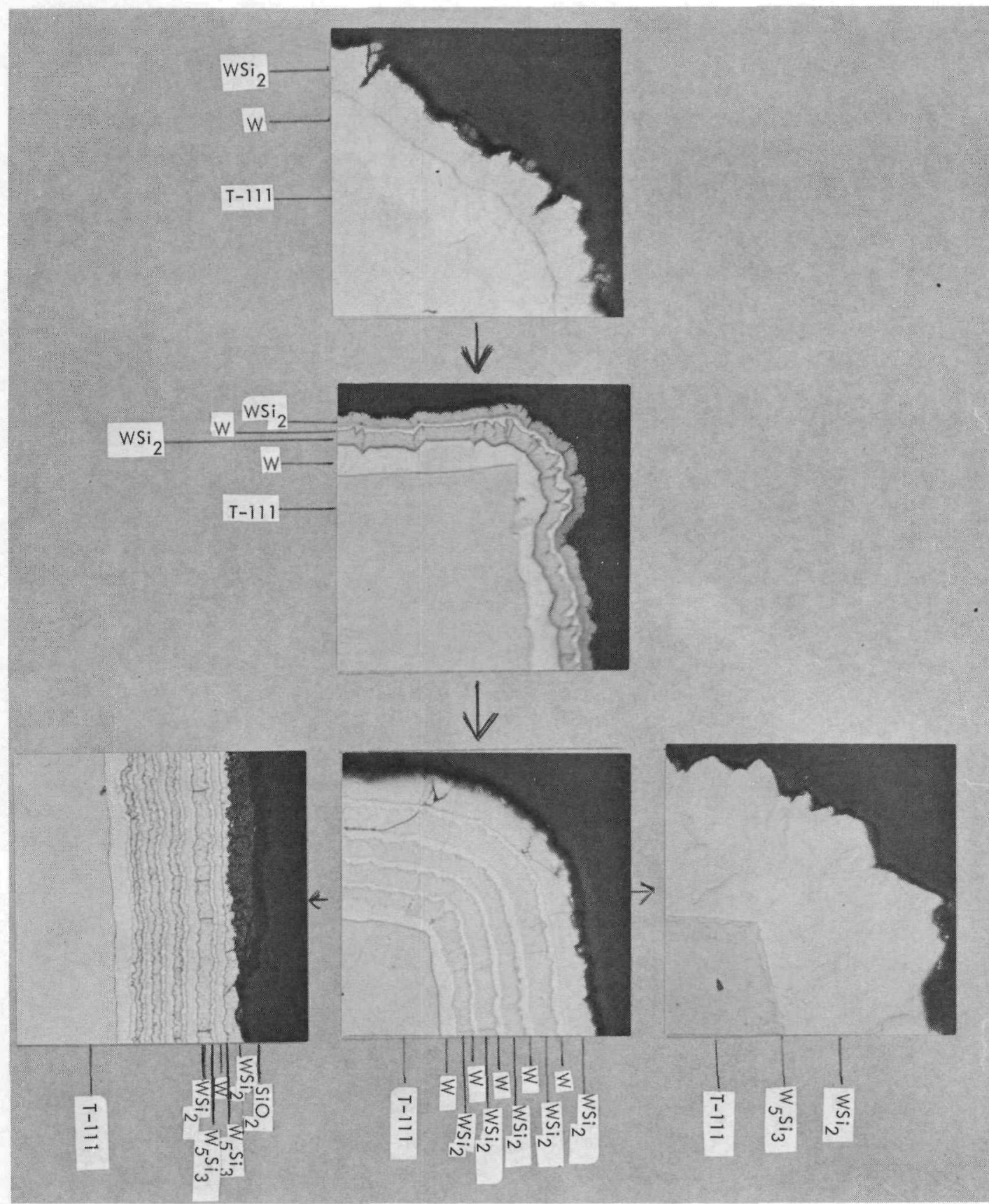

$500 \times$ (Reduced)

FIGURE 2

Metallographic Structures Showing Multi-Layered Oxidation Resistant Coatings 
(20) Astronuclear

WANL-TMI-1763

Title:

OUT-OF-VACUUM ELECTRON BEAM WELDING

Project No.:

$6-59316-46$

F. D. Seaman

I. Objective: Provide support to the development and introduction of out-of-vacuum electron beam technology.

\section{Technical Progress}

The objective resolved itself into specific tasks as experience was gained in the building of equipment (Capital Funds Appropriation E-6103-1 and NAS 8-1 1929 Phase II) and in actual welding (NAS 8-11929 Phase I).

Task 1 - Redesign of Power Supply and Case to Accommodate a Substitute Transformer When, after several months of negotiations, it appeared that Baltimore Aerospace would not supply the transformer for the welding being built on E-6102-1, a task force was inaugurated to determine new sources within the corporation. This group learned that only Baltimore, Headquarters Manufacturing Laboratory, and R\&D had actually deal $t$ with the unusual construction required by the portable welder concept. The required construction is characterized by the use of solid organic insulation in the presence of relatively high frequencies (400-1000 cps are used to miniaturize the bulky iron core) and unusually high turn-to-turn and layer-to-layer voltages. Voltages as high as $10 \mathrm{~V}$ and $2600 \mathrm{~V}$ respectively must be dealt with for the application. The problem arises when the several opposing requirements that result are placed on the impregnating material and process. The insulating material must be of low viscosity to flow between the wires, but it must have a high dielectric strength. Once in place, it is subject to void formation through solvent evolution and through the mechanical tearing action when the metal-uncured plastic composite goes through the curing cycle. Such damage is undetectable until the residue in the cavities is subjected to relatively high frequency fields and voltages which cause corona, ionization, 
decomposition into such materials as carbon and ultimately failure.

Recognition of these engineering fundamentals, coupled with a quantitative study by Headquarters Manufacturing Laboratories, lead to a conservative design that, on test, did meet and exceed vol tage levels at the highest frequencies without evidence of corona in the cavities. The design parameters were then confirmed by the Task Force in a meeting with Baltimore Surface Division.

With this basis for assurance that a transformer could be procured, the entire support structure of the power supply was redesigned around a simple center skewer with inexpensive spiders holding the ring-like capacitors and rectifiers. Once designed, this unit was assembled in one day compared to two weeks for the more compact Baltimore design.

The auxiliary control circuits were redesigned around the simplified circuits that evolved from Task 2 but could be even further refined since the larger more open construction of this new arrangement left room for a separate isolation transformer for the filament current and another for the bolt voltage.

Finally, a pressure vessel was designed using readily available flanges and domes.

At the end of the year the prototype (built on E-6102-1) had operated in air at voltages equivalent to $200,000 \mathrm{~V}$.

Results: This six-month study has led to the following improvements in the technology associated with the portable welder concept.

1. The fundamental problem associated with light weight gas insulated transformers was identified. This information was used to complete a transformer for E-6102-1 and also, through broad participation on the task force, to support the design of the transformer for the Self-Contained welders. This latter information assisted in obtaining and prosecuting NAS 8-20567 and its follow-on NAS 8-20678 using $2 \mathrm{Kw} \mathrm{20,000} \mathrm{volt} \mathrm{transformers} \mathrm{weighing} \mathrm{only}$ four pounds. 
2. The redesigned unit can be assembled in days instead of weeks and the support structure has been reduced in cost. The estimated value of the power supply (without case or controls) was $\$ 34,000$ in April and it can now be built for $\$ 20,000$ ( $\$ 12,000$ hardware and case plus $\$ 7,900-\$ 8,000$ labor and overhead).

3. Accessibility for service and adjustment has been improved.

Future Effort: The redesign to the less compact power supply and the resulting necessity for a case meeting ASME pressure vessel codes has added 18 inches in length and 180 pounds to the power supply. Studies will be made to determine if the packing factor should be increased with a lower weight power supply or the gas pressure should be reduced by using better dielectrics and the case redesigned to represent minimum weight for that structure.

\section{Task 2 - Redesign of the Auxiliary Control System} After completion of the acceptance tests on the NAS 8-11929 Phase II equipment a period of operation was experienced during which the poor transmission of the beam and the low emission from the cathode suggested that the Baltimore designed, multichannel, optical telemetry system was not controlling the diode emission system. At least six repairs were made of parts that were found to be malfunctioning and oscilloscope observation of that beam which was emitted showed high frequency, high voltage transients. These transients could have coupled into any of the over one hundred circuits of the control system reducing component life to an unpredictable and low value. Experience with the first six repairs suggested that a complete replacement of the electronic components was in order. At this point, a decision was made to replace the Baltimore system with a simpler system since the first repairs had been preceded by a long complex diagnostic study to isolate the affected circuit and then the particular component. Simple systems had been used on two previous similar welders - the optical telemetry system was an innovation on the NASA welder aimed at accommodating filament changes which had been anticipated but not actually observed. 
The redesign involved utilizing the single isolation transformer which had been integrated into the compact circuit. Previous systems used two transformers (one for filament heating and one for the filament-cathode potential). A proportioning network was developed on a breadboard to accomplish this over the entire operating range without affecting transformer performance while operating at 150,000 volts in an existing chassis. A single power supply was built to furnish the signal to this system from ground potential. The control panel of the welder was redesigned to accommodate the new system and to el iminate about 100 new, unused parts from the Baltimore design.

The above system was installed on a temporary basis and was operated through the last four months of the year with no failures. The regulation of the ground potential power supply was observed to be out of specification but adequate. The single control adjustment is very sensitive but will be modified in the final packaging and installation. All components for the final installation were procured against this task.

Results: This six-month study has permitted the NAS 8-11929 Phase I welding study to continue. Certain specific advantages can be claimed.

1. The new control contains only two circuits and a proportioning network involving only 15 components in all. Thus far, it has not failed but isolation of defective components should not require more than 30 minutes as opposed to 24 hours on the earlier unit (a period which might have had to be multiplied several times since more than one of the one hundred circuits might have been involved).

2. The stability of the new circuit is better than the original by a factor of two.

Future Effort: This work is complete. 
Task 3: Design of New Beam Exit Designs

As applications discussions were initiated, as part of the year's development program, it became evident that access to many common weldments was not possible because of the short gun-to-work piece spacing (about $1 / 4-1 / 2$ inch) and the fact that the beam exists from the center of the flat bottom of a four-inch diameter cylindrical structure housing the first and second nozzles. Access to the joint is a major application criterion in selecting welding processes and equipment. For many years MIG and TIG process applications were affected because the original, cumbersome, watercooled nozzles would not reach where coated electrodes could reach. Many in-vacuum, high voltage electron beam welders have been justified because the long beam could reach into some recessed area.

The initial study of how to meet th is market requirement considered four alternatives as follows:

1. Enter the "free beam" vacuum electron beam market: Any overt move to enter the vacuum electron beam market was set aside because in this area Westinghouse holds no special technological trump card. In fact, the present electron optical system is not as good as Hamilton Standard's (a situation which should be rectified as soon as possible - perhaps when the R\&D No. 1 unit is rebuilt to the Mark II configuration). Of course, a potential customer is advised that he can always operate a non-vacuum welder in vacuum conditions if there is some special reason to do so. This was the case in the Lockheed proposal A-496.

2. Enter the Semi-Vacuum Field: Westinghouse may have a technical advantage here in its highly efficient orifice system and stable emitter. However, these units are used mainly for production and are not justifiable as a development item in the WANL product line unless we could be permitted to sell them. A low cost $(\$ 25-50,000)$ unit would be involved.

3. Modify the End of the Welder: A conical nozzle appeared to be the most appropriate solution because (a) it improved access and (b) it might 
modify the phenomena immediately under the orifice by allowing vapor and heat to escape more easily or (c) it wuld allow the welder to be placed at an angle other then $90^{\circ}$ from the work piece.

Accordingly, a conical nozzle of $60^{\circ}$ included angle was built and applied to the NASA welder for test. Access to most weld tooling was achieved and it appeared that shallow ribs could be welded. Welding phenomena did not appear to be affected. The introduction of the nozzle required that the bolt cathode be extended and transmission appeared lower. Because of the latter observations, the nozzle was returned to R\&D for study and will be tested again when they establish the cause.

Additionally, an application discussion with a potential customer revealed a need for welding in shallow, but narrow grooves between finished precision gears. The non-vacuum welder had an advantage over the free beam welder in that, because of the beam control necessary to get through the orifices, the precise point of exit is known. Tooling, therefore, becomes a mechanical problem not unlike locating a tool for a plunge cut. A nozzle was designed and tested on simulated gear blanks. Precision measurements indicated no distortion either along the axis or in the form of rotation. Contact is being maintained with the customer pending his decision regarding the welded design.

Results: This three-month program produced two improved-access beam exit designs. A second nozzle has been built which illustrates a clear advantage of the non-vacuum unit over the vacuum unit - specifically ease of tooling for precise beam placement.

Future Effort: The conical nozzle will be offered to NASA as an accessory as soon as the cause of the effect on transmission is understood and corrected.

\section{Summation of Costs}

A total of $\$ 23,686$ was spent in 1966 . 
IV. Benefit to WANL

This effort, supplemented by the funds being directed into allied projects using E-order dollars, 1-monies at Research, and customer contract money, has created a good basis for additional growth and technical improvement.

Additional contract support was received from NASA-Huntsville bringing the total dollars, to-date, to slightly over $\$ 500,000$ in electron beam technology. Many contacts have been made with the aerospace industry which permit us to have an up-to-date understanding of industry progress and problems. 